\title{
ANTHROPOMETRIC STUDY ON FOOT AND THEIR DIGITAL PRINT FOR DETERMINATION OF STATURE ON AN EGYPTIAN POPULATION SAMPLE
}

\author{
Nadia kotb, Saied Abul-Nasr, Mona M Ali and Fatma Nada \\ Department of forensic medicine and clinical toxicology, Cairo University
}

\begin{abstract}
:
In forensic investigation difficulties are being experienced in the regarding stature of bodies dismembered in mass destruction. So as to eliminate these difficulties, new methods should be developed. The aim of this study is to develop formulae for estimation of the stature through foot measurements and foot digital print parameters and compare the accuracy between both. Material and methods, the length, width and foot heel width measurements of the right foot were taken adding to these measures (for print parameters) each foot print toe length as well as stature have been taken from 160 adult subjects ( 80 males and 80 females). Results revealed that, in males, stature and foot measurements were higher than in females. The highest correlation was observed in the right foot length when stature and foot measurement relations were evaluated. Formulae were obtained by using multiple regression analysis for stature estimation for both anthropometric measures and digital print parameters showing lower standard error of estimation for anthropometric method. Key words: right foot, anthropometric measures and digital print.
\end{abstract}

\section{INTRODUCTION:}

In forensic investigations, gender, age, race and stature are evaluated to determine the identity. Stature estimations are easily done with primary anatomic structures in intact corpses. It is very hard to identify parted bodies especially after disasters where people are dead and became unrecognizable. Variable methods have been developed to cope with these difficulties. Besides, there are some studies on the stature estimation from foot measures (Nagesh \& Kumar, 2006).

Stature estimation provides an idea about the size of the person. Due to the algometric relationship of the body parts with each other, the stature can be estimated from almost all the bones of the skeleton. Forensic anthropologists worldwide have attempted to estimate stature from various bones. Long bones of the lower extremity are known to give more accurate estimates of stature as these directly contribute to the stature of a person. Other long bones such as the bones of the upper extremity such as humerus, ulna and radius can also be used to estimate the stature of a person. There are two methods for estimation of stature from the skeletal remains; anatomical method and mathematical method. The anatomical method is the most accurate method as it involves the complete skeleton for stature estimation. The mathematical method involves the use of certain statistical formulae in estimation of stature (Krishan \& Kanchan, 2013).

In this study, we aimed to show the relation of foot size with stature, and try to develop formulae for stature estimation when necessary from both 
anthropometric measures and digital print parameters and to assess the accuracy of both methods.

\section{MATERIAL \& METHODS}

The present study is a cross sectional study that was conducted on 160 adult subjects above 21 years old (80 males and 80 females). And they are divided into 2 groups (each group was 80 cases; 40 males and 40 females):

- Group 1: From 21 to 50 year old.

- Group 2: Above 50 years old.

- Anthropological measurements from right foot, and their digital prints, were taken to determine stature.

\section{A) Subjects Inclusion Criteria:}

These subjects should fulfill certain criteria for choice:

* Age is above 21 years old (the age of stopping growing in stature i.e union of the epiphysis around joints as knee).

*Both sexes (male and female).
* Egyptians.

B) Subjects Exclusion Criteria:

* Subjects below 21 years old.

* Subjects with definite history of trauma, fracture and orthopedic diseases.

* Any foot operations.

* Patients with any debilitating diseases as poliomyelitis or rheumatoid diseases.

* Disabled cases.

*Deformity of the vertebral column or limbs.

*Congenital or endocrinological diseases or any disease that causes asymmetry.

Stature: is the distance from the vertex to the foot, this was done by using the scale length (stadiometer) fig. (1) (Zt-150a, medical therapy company).The subjects were measured bare-foot, the head was at right angle with the body, and the results were documented in $\mathrm{cm}$.

Figure (1): scale length (stadiometer). 
From right foot, the following anthropometric measures were taken using Mitutoya digital caliber fig.(2):

1- Foot length (FL) The maximum distance between the heel (pternion) and longest toe (akropodian).

2- Foot breadth (FB) The distance between the most prominent point on the medial side of the foot to the most prominent point on the lateral side (which corresponds to the heads of the first to fifth metatarsals.

3- Foot Heel breadth (FHB) The maximum distance from the most protruding point on the medial surface of the heel to the corresponding protrusion on the lateral surface of the heel.

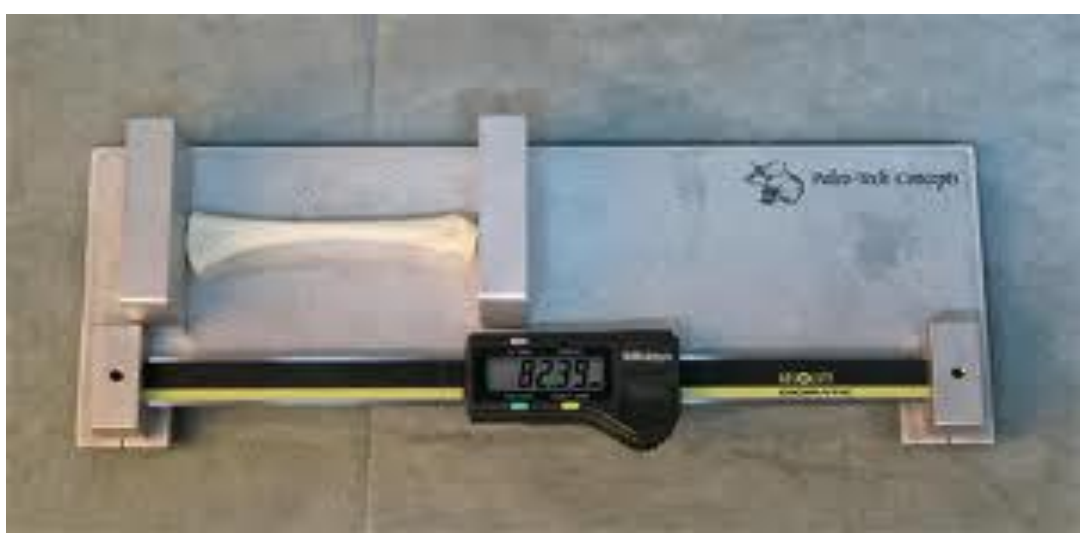

Figure (2): Digital caliper having 0.01 millimeter (mm) sensitivity (Mitutoya).

Print parameters:

The prints were taken from right foot by a highly resolution samsung camera, 8 megapexil fig. (3), good illumination and from a suitable constant distance $(30 \mathrm{~cm})$ then to obtain the most accurate approximation of the print, the scanned images were edited using the Photoshop1 on a computer.
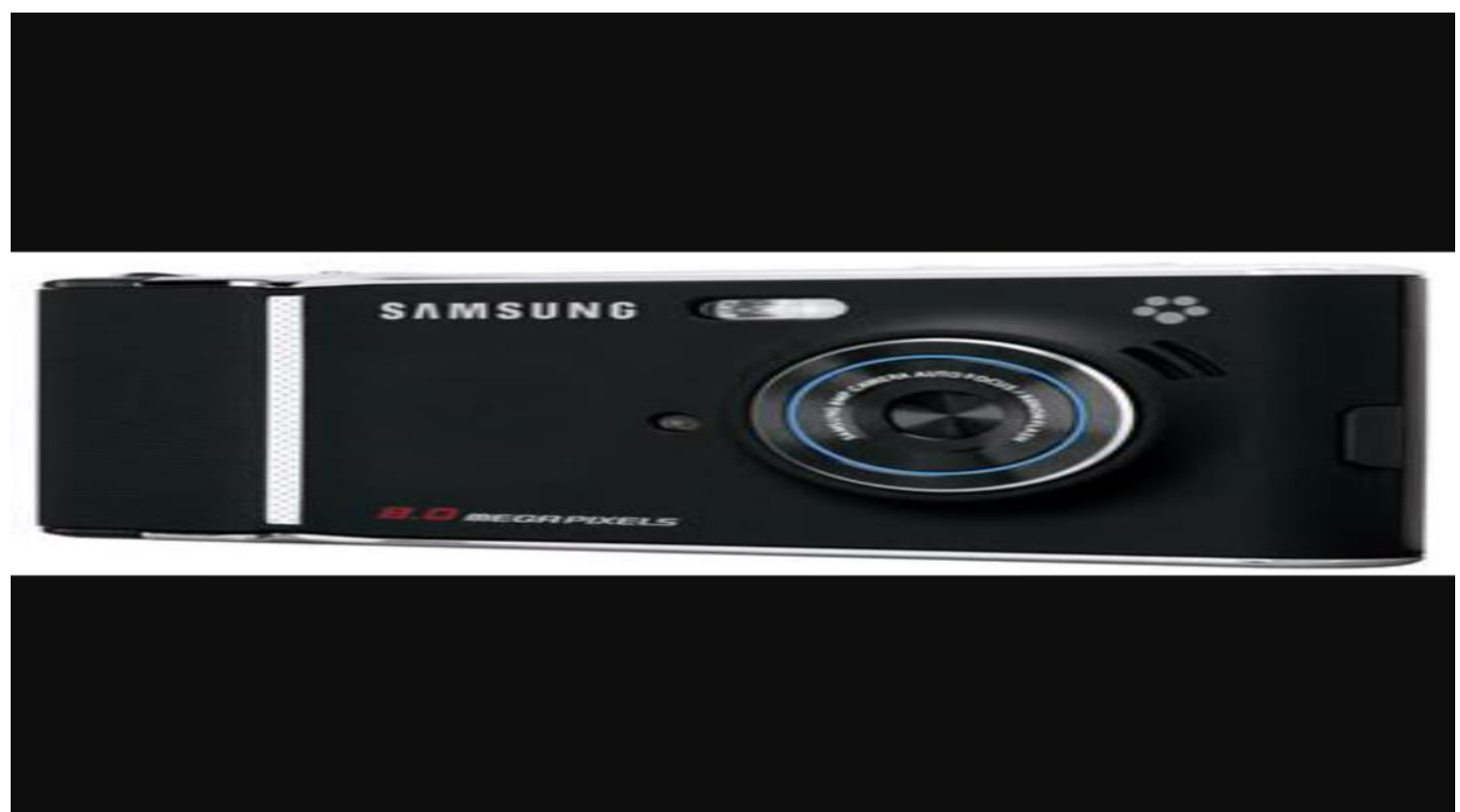

Figure (3): Samsung 8 megapexil camera. 
The following measures were taken

From RT foot print fig (4):

Foot print length (FPL).

Foot print breadth (FPB).
Foot print heel breadth (FPHB).

Each foot print- toe length (FPT1L, FPT2L, FPT3L, FPT4L and FPT5L).
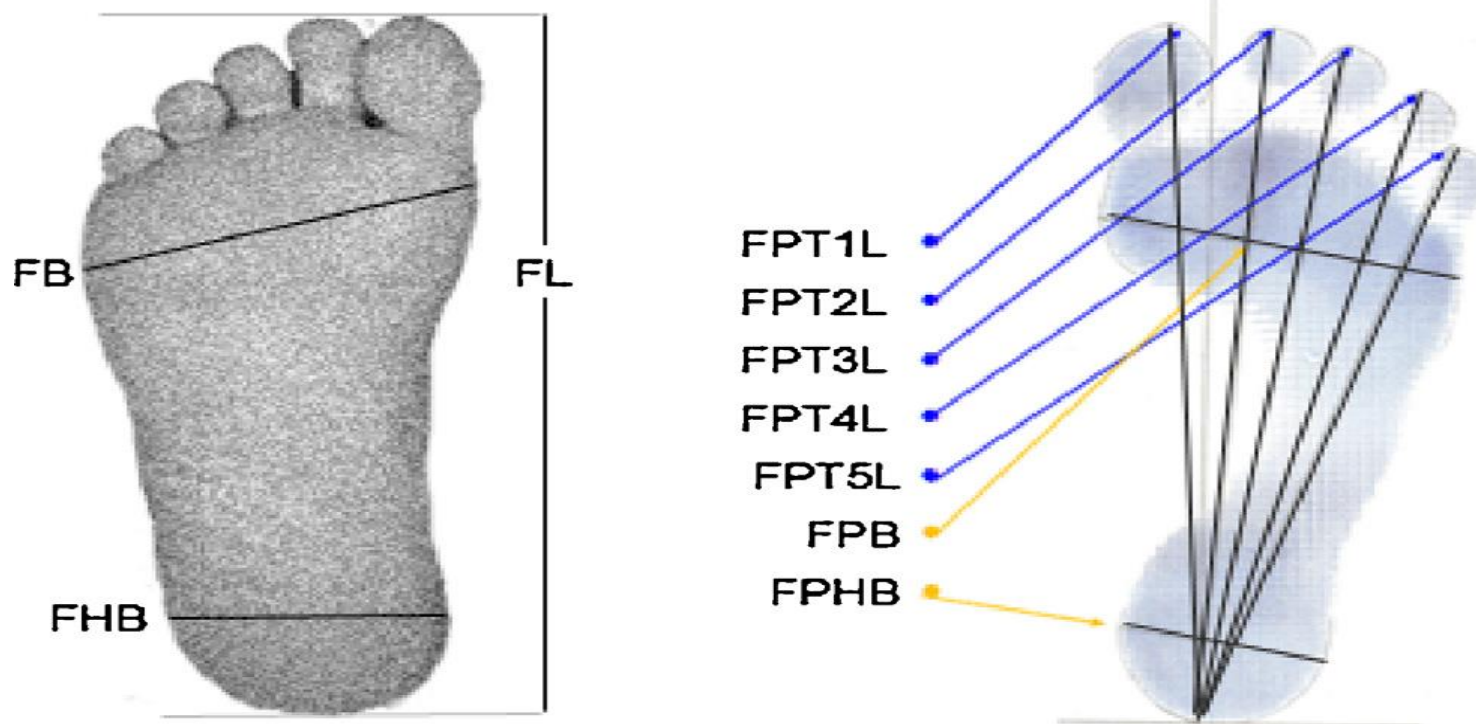

Figure (4): Plantar view illustrating the anthropometric (left) and podogram (right) measurements used in this study

Statistical analysis:

Data were coded and entered using the statistical package SPSS version 22. Data was summarized using mean, standard deviation, minimum and maximum for quantitative variables and frequencies (number of cases) and relative frequencies (percentages) for categorical variables. Correlations between variables were done using
Pearson correlation coefficient. Univariate and then multivariate linear regression were done to detect stature. $\mathrm{P}$-values less than 0.05 were considered statistically as low significant, less than 0.01 were considered statistically as moderate significant and less than 0.001 were considered statistically as high significant (normal distribution).

\section{RESULTS:}

Table (1): Correlation between stature and foot anthropometric measures in group-1

\begin{tabular}{|l|l|l|}
\hline Parameter & & Stature \\
\hline \multirow{2}{*}{ FL } & $\mathrm{R}$ & $\mathbf{. 8 0 3}$ \\
\cline { 2 - 3 } & P value & $<\mathbf{0 . 0 0 1}$ \\
\hline \multirow{2}{*}{ FHB } & $\mathrm{R}$ & $\mathbf{. 5 6 7}$ \\
\cline { 2 - 3 } & P value & $<\mathbf{0 . 0 0 1}$ \\
\hline & $\mathrm{R}$ & $\mathbf{. 1 6 4}$ \\
\cline { 2 - 3 } & P value & $\mathbf{. 1 4 6}$ \\
\hline
\end{tabular}

-Significance: *p-value $<\mathbf{0 . 0 5}$.

-FL: foot length; FB: foot breadth and FHB: foot heel breadth.

-R: regression coefficient. 
Table (1) showed high significant positive correlation $(\mathrm{P}<0.001)$ between stature and foot length (FL) and foot breadth (FB) . However non-significant correlation was found between stature and foot-heel breadth (FHB).

Table (2): Correlation between stature and foot digital print parameters in group-1

\begin{tabular}{|c|c|c|}
\hline \multicolumn{2}{|l|}{ Parameter } & Stature \\
\hline \multirow[t]{2}{*}{ FPB } & $\mathbf{R}$ & .150 \\
\hline & $P$ value & .185 \\
\hline \multirow[t]{2}{*}{ FHPB } & $\mathbf{R}$ & .005 \\
\hline & P value & .964 \\
\hline \multirow[t]{2}{*}{ FPT1L } & $\mathbf{R}$ & .407 \\
\hline & P value & $<0.001$ \\
\hline \multirow[t]{2}{*}{ FPT2L } & $\mathbf{R}$ & .475 \\
\hline & $P$ value & $<0.001$ \\
\hline \multirow[t]{2}{*}{ FPT3L } & $\mathbf{R}$ & .436 \\
\hline & P value & $<0.001$ \\
\hline \multirow[t]{2}{*}{ FPT4L } & $\mathbf{R}$ & .434 \\
\hline & P value & $<0.001$ \\
\hline \multirow[t]{2}{*}{ FPT5L } & $\mathbf{R}$ & .424 \\
\hline & P value & $<0.001$ \\
\hline
\end{tabular}

-Significance: *p-value $<0.05$.

-FPL: foot print length; FPB: foot print breadth; FHPB: foot heel print breadth; FPT1L: foot print toe 1 length; FPT2L: foot print toe 2 length; FPT3L: foot print toe 3 length; FPT4L; foot print toe 4 length and FPT5L: foot print toe 5 length.

-R: regression coefficient.

Table (2) showed a high significant positive correlation between stature and FPT1L, FPT2L, FPT3L, FPT4L and FPT5L. While non significant correlation was found with other parameters. However, correlation coefficients of the length measurements were found to be higher than that of breadth measurements.

Table (3): Correlation between stature and foot anthropometric measures in group-2

\begin{tabular}{|l|l|l|}
\hline Parameter & & Stature \\
\hline \multirow{2}{*}{ FB } & R & $\mathbf{6 6 5}$ \\
\cline { 2 - 3 } & P value & $<0.001$ \\
\hline \multirow{2}{*}{ FHB } & R & $\mathbf{. 5 0 6}$ \\
\cline { 2 - 3 } & P value & $<0.001$ \\
\hline & R & $\mathbf{. 5 5 1}$ \\
\cline { 2 - 3 } & P value & $<0.001$ \\
\hline
\end{tabular}

-Significance: *p-value $<0.05$.

FL: foot length; FB: foot breadth and FHB: foot heel breadth.

$-R$ : regression coefficient.

Table (3) showed a high significant stature and FL, FB and FHB. positive correlation $(\mathrm{P}<0.001)$ between 
Table(4): Correlation between stature and foot digital print parameters in group-2.

\begin{tabular}{|c|c|c|}
\hline \multicolumn{2}{|c|}{ Parameter } & Stature \\
\hline FPB & $\mathbf{R}$ & .030 \\
\hline & P value & .819 \\
\hline \multirow[t]{2}{*}{ FHPB } & $\mathbf{R}$ & .068 \\
\hline & $P$ value & .606 \\
\hline \multirow[b]{2}{*}{ FPT1L } & $\mathbf{R}$ & .154 \\
\hline & P value & .241 \\
\hline \multirow{2}{*}{ FPT2L } & $\mathbf{R}$ & .074 \\
\hline & P value & .577 \\
\hline \multirow[t]{2}{*}{ FPT3L } & $\mathbf{R}$ & .119 \\
\hline & $P$ value & .366 \\
\hline \multirow[t]{2}{*}{ FPT4L } & $\mathbf{R}$ & .130 \\
\hline & $P$ value & .323 \\
\hline \multirow[t]{2}{*}{ FPT5L } & $\mathbf{R}$ & .103 \\
\hline & P value & .436 \\
\hline
\end{tabular}

-Significance: *p-value $<0.05$.

FPL: foot print length; FPB: foot print breadth; FHPB: foot heel print breadth; FPT1L: foot print toe 1 length; FPT2L: foot print toe 2 length; FPT3L: foot print toe 3 length; FPT4L; foot print toe 4 length and FPT5L: foot print toe 5 length. -R: regression coefficient.

Table (4) showed non significant correlation between stature and all

digital print parameters.

Table (5): Univariate linear regression to determine stature in group 1 using anthropometric measures

\begin{tabular}{|l|l|l|l|l|}
\hline Variable & Equation & R & \pm SEE & P value \\
\hline FL & $\mathbf{5 4 . 2 7 6 + 4 . 7 1 7 ~ F L ~}$ & $\mathbf{. 8 0 3}$ & $\mathbf{5 . 7 8 9 7 7 7}$ & $<\mathbf{0 . 0 0 1}$ \\
\hline FB & $\mathbf{1 0 1 . 8 1 2 + 7 . 0 0 3 ~ F B ~}$ & $\mathbf{. 5 6 7}$ & $\mathbf{8 . 0 0 1 2 7 4}$ & $<\mathbf{0 . 0 0 1}$ \\
\hline FHB & $\mathbf{1 5 0 . 5 6 6 + 2 . 6 8 5 ~ F H B}$ & $\mathbf{. 1 6 4}$ & $\mathbf{9 . 5 8 1 9 3 9}$ & $\mathbf{1 4 6}$ \\
\hline
\end{tabular}

-Significance: *p-value $<0.05$.

FL: foot length; FB: foot breadth and FHB: foot heel breadth.

-SEE: standard error of estimation.

-R: regression coefficient.

Regression equations have been computed separately, for each measurement of foot. A computer analysis of data enabled the calculation of regression coefficients ' $a$ ' and ' $b$ ', where ' $a$ ' is the regression coefficient of the dependent variable i.e. stature and ' $b$ ' is the regression coefficient of the independent variable i.e. foot length or foot breadth. Hence, stature $=\mathrm{a}+$ $\mathrm{bx}$; where $\mathrm{x}=$ measurement of foot.

Regression equations for each individual foot anthropometric measurements were analysed. The standard error of estimate (SEE) along with linear regression equations for foot length, foot breadth and foot heel breadth were taken in both sexes. The SEE predicts the deviations of estimated stature from the actual 
stature. A low value indicates greater reliability in the estimated stature.

The standard error of the estimate ranged between \pm 5.789777 for FL and \pm 9.581939 for FHB. In assessing the accuracy of our simple linear regression models, the standard error of the estimate (SEE) was lowest using the measurement of FL.

Table (6): Univariate linear regression to determine stature using digital print parameters in group-1

\begin{tabular}{|l|l|l|l|l|}
\hline Variable & Equation & $\mathbf{R}$ & \pm SEE & P value \\
\hline FPB & $155.839+1.629$ FPB & .150 & $\mathbf{9 . 6 0 3 8 8 8}$ & .185 \\
\hline FHPB & $166.215+.050$ FHPB & .005 & $\mathbf{9 . 7 1 3 3 2 2}$ & .964 \\
\hline FPT1L & $129.717+2.298$ FPT1L & .407 & $\mathbf{8 . 8 7 0 3 7 9}$ & $<0.001 * * *$ \\
\hline FPT2L & $131.917+2.208$ FPT2L & .475 & $\mathbf{8 . 5 4 8 9 5 8}$ & $<0.001 * * *$ \\
\hline FPT3L & $128.714+2.568$ FPT3L & .436 & $\mathbf{8 . 7 4 1 1 3 5}$ & $<0.001 * * *$ \\
\hline FPT4L & $129.252+2.710$ FPT4L & .434 & $\mathbf{8 . 7 5 2 7 4 3}$ & $<0.001 * * *$ \\
\hline FPT5L & $130.648+2.814$ FPT5L & $\mathbf{. 4 2 4}$ & $\mathbf{8 . 7 9 6 9 2 9}$ & $<0.001 * * *$ \\
\hline
\end{tabular}

-Significance: *p-value $<0.05$ low, $* *$ p-value $<0.01$ moderate, $* * *$ p-value $<0.001$ high.

FPL: foot print length; FPB: foot print breadth; FHPB: foot heel print breadth; FPT1L: foot print toe 1 length; FPT2L: foot print toe 2 length; FPT3L: foot print toe 3 length; FPT4L; foot print toe 4 length and FPT5L: foot print toe 5 length. -SEE: standard error of estimation.

-R: regression coefficient.

In assessing the accuracy of our simple linear regression models, the standard error of estimation (SEE) was lowest using the measurement of FPT2L (a low value indicates greater reliability in the estimated stature), then FLT3L was \pm 8.7441135 (with $r=0.436$ and highly significant p-value $<0.001)$. The highest SEE was for FHPB.

Table (7): Univariate linear regression to determine stature in group-2 using anthropometric measures

\begin{tabular}{|l|l|l|l|l|}
\hline Variable & Equation & R & \pm SEE & P value \\
\hline FL & $\mathbf{8 3 . 2 1 6 + 3 . 3 2 7 ~ F L ~}$ & $\mathbf{. 6 6 5}$ & $\mathbf{6 . 0 6 2 8 8 0}$ & $<0.001$ \\
\hline FB & $\mathbf{1 0 6 . 9 6 7 + 5 . 9 6 2}$ FB & $\mathbf{. 5 0 6}$ & $\mathbf{7 . 0 0 7 9 8 1}$ & $<0.001$ \\
\hline FHB & $\mathbf{1 1 7 . 1 5 4 + 7 . 4 6 9}$ FHB & $\mathbf{. 5 5 1}$ & $\mathbf{6 . 7 7 6 3 0 9}$ & $<0.001$ \\
\hline
\end{tabular}

-Significance: *p-value $<0.05$.

FL: foot length; FB: foot breadth and FHB: foot heel breadth.

-SEE: standard error of estimation.

-R: regression coefficient.

In assessing the accuracy of our simple linear regression models, the standard error of estimation (SEE) was lowest using the measurement of FL, then FHB and the highest SEE was for FB. 
Table (8): Univariate linear regression to determine stature using print parameters in group-2

\begin{tabular}{|l|l|l|l|l|}
\hline Variable & Equation & $\mathbf{R}$ & \pm SEE & P value \\
\hline FPB & $\mathbf{1 5 9 . 4 9 7 + . 3 0 6 ~ F B P ~}$ & $\mathbf{. 0 3 0}$ & $\mathbf{8 . 1 1 8 6 2 7}$ & $\mathbf{. 8 1 9}$ \\
\hline FHPB & $\mathbf{1 5 7 . 6 0 3 + . 9 9 6}$ FHPB & $\mathbf{. 0 6 8}$ & $\mathbf{8 . 1 0 3 5 7 1}$ & $\mathbf{. 6 0 6}$ \\
\hline FPT1L & $\mathbf{1 5 6 . 4 8 7 + . 3 1 3}$ FPT1L & $\mathbf{. 0 7 3}$ & $\mathbf{8 . 1 0 0 6 2 2}$ & $\mathbf{. 5 7 9}$ \\
\hline FPT2L & $\mathbf{1 5 6 . 4 5 4 + . 3 2 2}$ FPT2L & $\mathbf{. 0 7 4}$ & $\mathbf{8 . 1 0 0 3 4 4}$ &. $\mathbf{5 7 7}$ \\
\hline FPT3L & $\mathbf{1 5 3 . 0 4 0 + . 5 6 4}$ FPT3L & $\mathbf{. 1 1 9}$ & $\mathbf{8 . 0 6 4 7 6 9}$ & $\mathbf{. 3 6 6}$ \\
\hline FPT4L & $\mathbf{1 5 2 . 2 8 7 + . 6 5 8}$ FPT4L & $\mathbf{. 1 3 0}$ & $\mathbf{8 . 0 5 3 6 5 6}$ & $\mathbf{. 3 2 3}$ \\
\hline FPT5L & $\mathbf{1 5 4 . 9 4 1 + . 5 1 2}$ FPT5L & $\mathbf{. 1 0 3}$ & $\mathbf{8 . 0 7 9 5 1 1}$ & $\mathbf{. 4 3 6}$ \\
\hline
\end{tabular}

-Significance: *p-value $\mathbf{0 . 0 5}$.

FPL: foot print length; FPB: foot print breadth; FHPB: foot heel print breadth; FPT1L: foot print toe 1 length; FPT2L: foot print toe 2 length; FPT3L: foot print toe 3 length; FPT4L; foot print toe 4 length and FPT5L: foot print toe 5 length.

-SEE: standard error of estimation.

-R: regression coefficient.

In assessing the accuracy of our simple linear regression models, the standard error of estimation (SEE) was lowest using the measurement of FPT4L, and the highest SEE was for FPB. But still it was non-significant.

Table (9): Multivariate linear regression to determine stature in group-1 from anthropometric measures

\begin{tabular}{|c|c|c|c|c|}
\hline $\begin{array}{c}\text { Anthropometric } \\
\text { measures }\end{array}$ & B & $P$ value & $\mathbf{R}$ & SEE \\
\hline \begin{tabular}{l|l} 
& (Constant)
\end{tabular} & 41.577 & \multirow{4}{*}{0.000} & \multirow{4}{*}{.882} & \multirow{4}{*}{4.87382} \\
\hline FL & 2.776 & & & \\
\hline FB & .618 & & & \\
\hline FHB & $-1.576-$ & & & \\
\hline
\end{tabular}

Significance: *p-value $<0.05$.

FL: foot length; FB: foot breadth and FHB: foot heel breadth.

-SEE: standard error of estimation.

-R: regression coefficient.

Regression equation to determine stature in group-1 using anthropometric measures:

Stature $=2.776 \times \mathrm{FL}+0.618 \times \mathrm{FB}-$ 1.576×FHB.

Multivariate regression was done to assess if stature prediction accuracy was improved by utilizing multiple variables. Multiple regression equations for the estimation of stature were taken from different combinations of dimensions RT foot. The variables generally weighed most strongly in the multiple regression models. It is

important to note that stepwise discriminant function analyses are known to be sensitive to small variations in the predictor variables, which may affect the functions of comprising variables selected in this manner. It is observed that the multiple regression equations reveal lower values of SEE $( \pm 4.87382)$ and $(r=.882)$ than the values given by linear regression equations. Interpretation suggested that the multiple regression equations are better indicators of stature estimation. 
Table (10): Multivariate linear regression to determine stature in group-2 from anthropometric measures.

\begin{tabular}{|c|c|c|c|c|}
\hline $\begin{array}{c}\text { Anthropometric } \\
\text { measures }\end{array}$ & B & $P$ value & $\mathbf{R}$ & \pm SEE \\
\hline \begin{tabular}{|l|} 
(Constant) \\
\end{tabular} & 62.379 & \multirow{4}{*}{$<0.001$} & \multirow{4}{*}{0.789} & \multirow{4}{*}{5.42398} \\
\hline FL & 1.759 & & & \\
\hline FB & -.548 & & & \\
\hline FHB & 1.009 & & & \\
\hline
\end{tabular}

Significance: *p-value $₫ \mathbf{0 . 0 5}$.

FL: foot length; FB: foot breadth and FHB: foot heel breadth.

-SEE: standard error of estimation.

-R: regression coefficient.

Regression equation to determine stature in group-2 using anthropometric measures:

\section{Stature $=$}

$1.759 \times$ FL- $0.548 \times \mathrm{FB}+1.009 \times \mathrm{FHB}$.

It is observed that the multiple regression equations reveal lower values of SEE $( \pm 5.42398)$ than the values given by linear regression equations, and higher correlation coefficient $(\mathrm{r}=.0 .789)$.

Table (11): Multivariate linear regression to determine stature in group-1 from print parameters.

\begin{tabular}{|c|c|c|c|c|}
\hline & B & P value & $\mathbf{R}$ & \pm SEE \\
\hline (Constant) & 123.894 & \multirow{8}{*}{.001} & \multirow{8}{*}{.644} & \multirow{8}{*}{8.13829} \\
\hline FPB & $-3.068-$ & & & \\
\hline FHPB & .119 & & & \\
\hline FPT1L & $-.607-$ & & & \\
\hline FPT2L & 1.751 & & & \\
\hline FPT3L & 6.133 & & & \\
\hline FPT4L & $-4.799-$ & & & \\
\hline FPT5L & .241 & & & \\
\hline
\end{tabular}

-Significance: *p-value $\mathbf{} 0.05$.

FPL: foot print length; FPB: foot print breadth; FHPB: foot heel print breadth; FPT1L: foot print toe 1 length; FPT2L: foot print toe 2 length; FPT3L: foot print toe 3 length; FPT4L; foot print toe 4 length and FPT5L: foot print toe 5 length.

-SEE: standard error of estimation.

$-R$ : regression coefficient.

Regression equation to determine stature in group 1 using print measures:

\section{Stature $=$}

$3.068 \times \mathrm{FPB}+0.119 \times \mathrm{FHPB}-0.607 \times \mathrm{FPT} 1 \mathrm{~L}+1.751 \times \mathrm{FPT} 2 \mathrm{~L}+6.133 \times \mathrm{FPT} 3 \mathrm{~L}-$

$4.799 \times$ FPT4L $+0.241 \times$ FPT5L

It is observed that the multiple regression equations reveal lower values of $\operatorname{SEE}( \pm 5.42398)$ than the values given by linear regression equations, and higher correlation coefficient $(\mathrm{r}=.0 .789)$. 
Table (12): Multivariate linear regression to determine stature using digital print parameters in group-2

\begin{tabular}{|c|c|c|c|c|}
\hline & B & P value & $\mathbf{R}$ & \pm SEE \\
\hline (Constant) & 136.595 & \multirow{8}{*}{.504} & \multirow{8}{*}{.480} & \multirow{8}{*}{8.08850} \\
\hline FPB & $-2.901-$ & & & \\
\hline FHPB & 3.411 & & & \\
\hline FPT1L & .005 & & & \\
\hline FPT2L & $-5.282-$ & & & \\
\hline FPT3L & 6.761 & & & \\
\hline FPT4L & .266 & & & \\
\hline FPT5L & $-1.145-$ & & & \\
\hline
\end{tabular}

-Significance: *p-value $<0.05$ low, $* *$ p-value $<0.01$ moderate, $* * * p$-value $<0.001$ high. FPL: foot print length; FPB: foot print breadth; FHPB: foot heel print breadth; FPT1L: foot print toe 1 length; FPT2L: foot print toe 2 length; FPT3L: foot print toe 3 length; FPT4L; foot print toe 4 length and FPT5L: foot print toe 5 length.

-SEE: standard error of estimation.

$-R$ : regression coefficient.

Regression equation to determine stature in group-2 using digital print measures:

Stature $=2.901 \times$ FPB $+3.411 \times$ FHPB $+0.005 \times$ FPT1L $-5.282 \times$ FPT2L $+6.761 \times$ FPT3L $+0.266 \times$ FPT4L -1.145× FPT5L.

It is observed that the multiple regression equations reveal higher values of SEE $( \pm 8.08850)$ than the values given by linear regression equations, and higher $\mathrm{r}=.0 .480$.

\section{DISCUSSION}

Regarding correlations between stature and right foot measurements in this study, the correlation coefficient was found to be greater with foot length than with foot breadth. These results were similar to the results obtained by Pandey \& Ujwal (2007). Also Ozden et al., 2005, found a weak and non-significant correlation between the stature and foot width., while Krishan \& Sharma (2007) in the North Indian population (Rajputs), found that bilateral hand and foot lengths in both males and females exhibit statistically significant correlation coefficient with stature. Moreover,
Sen \& Ghosh, 2008, indicated that foot length provided highest reliability and accuracy in estimating stature of an unknown individual. It could be concluded that dependence on bony prominence is more accurate than skin creases.

Similarly, linear regression model was fitted for stature estimation from FL and FB on adult Turkish individuals. Also linear regression equations for stature estimation were also calculated using FL and FB by researchers on measurements from Indians. Agnihotri et al. (2007), Krishan \& Sharma, (2007) and Kanchan et al. (2008). All these studies showed that the regression coefficients were statistically significant, which is in agreement with the results of the present study.

Also these results agree with Zeybek et al. (2008), who found that the accuracy of simple linear regression 
models for the FL was higher than FHB and FB.

It is observed that the multiple regression equations reveal lower values of SEE and higher $(r=.882)$ than the values given by linear regression equations. This suggested that the multiple regression equations are better indicators of stature estimation.

Similar observations were made by studies of Ozden et al. (2005), Agnihotri et al. (2007), Krishan \& Sharma (2007), Kanchan et al. (2008), Rastogi et al (2008) and Sen \& Ghosh (2008).

Regression equations for foot print parameters were analysed. In assessing the accuracy of our simple linear regression models, the standard error of estimation (SEE) was low using the (HPL and FPT2L) but higher for (HB and FPHB). These results agreed with the results by Krishan \& Sharma (2007), Kanchan et al. (2008) and Rastogi et al. (2008).

This study showed that linear correlation of prints showed slightly higher SEE than the anthropometric measures. This agreed with Cutler et al. (1987) and Meissner et al. (2007) who showed that using the print method was less accurate than anthropometric measures.

Regarding the comparison between anthropometric method and the digital print method for determination of stature in our study, the anthropometric method was more accurate as the standard error of estimation in linear regression for stature determination was lower. Although prints are still an imperfect representation of the actual measures, it is a promising area for future research.

\section{CONCLUSION}

It is worthwhile to mention here that the present study is a pioneer study in forensic anthropology among Egyptian sample. The study has successfully reported the relationships between stature, FL, and FB. Foot length had higher correlation with stature than foot breadth. Feet can provide good reliability in estimation of stature in forensic examinations. Multiple regression equations were better indicators of stature estimation than univariate regression as it revealed higher $r$ value and lower SEE values. Digital prints are still an imperfect representation of the actual stature but it is still a promising area for future research.

\section{REFERENCES}

Agnihotri, A.K.; Purwar, B; Googoolye, K.; Agnihotri, S. and Jeebun, N. (2007): Estimation of stature by foot length. J. For. Leg. Med.; 14 : 279-283.

Cutler, B.L.; Penrod, S.D. and Martens, T.K. (1987): The reliability of eyewitness identification: the role of system and estimator variables. Law Hum. Behav.; 11 : 233-258.

Kanchan, K.; Menezes, R.G.; Moudgil, R.; Kaur, R.; Kotian, M.S. and Garg, R.K. (2008): Stature estimation from foot dimensions. For.Sci. Int.; 179 : 241.e1-241.e5.

Krishan, K. and Kanchan, T. (2013): Stature and Build. In: Siegel JA, Saukko PJ, editors. Encyclopedia of Forensic Sciences. Waltham: Academic Press.; 1: 4953.

Krishan, K. and Sharma, A. (2007): Estimation of stature from 
dimensions of hands and feet in a north Indian population. J .For. Leg Med.; 14 : 327-332.

Meissner, C.A.; Sporer, S.L. and Schooler, J.W. (2007): Person descriptions as eyewitness evidence, in: Lindsay, R.C.L., Ross, D.F. Read, J.D. and Toglia, M.P. (Eds.), The Handbook of Eyewitness Psychology, vol. II Memory for People, Lawrence Erlbaum Associates, Mahwah, NJ.,33-34.

Nagesh, K.R. and Kumar, G.P. (2006): Estimation of stature from vertebral column length in South Indians, Leg. Med.; 8 : 269-272.

Ozden, H.; Balci, Y. ; Demirustu, C.; Turgut, A. and Ertugrul, $M$. (2005): Stature and sex estimate using foot and shoe dimension. For.Sci. Int.; 147 : 181-184.
Pandey, N. and Ujwal, N.S. (2007): Estimation of Stature from Dimension of Hand in Medical Students. For. Sci. Int.; 147: 181-184.

Rastogi, P.; Nagesh, K.R. and Yoganarasimha, K. (2008): Estimation of stature from hand dimensions of north and south Indians J. Forensic Sci \& crim.; 2(2): 2-11.

Sen, J. and Ghosh, S. (2008): Estimation of stature from foot length and foot breadth among Rajbanshi: An indigenous population of North Bengal. For. Sci. Int.; 181: 551-556.

Zeybek, G.; Ergur, I. and Demiroglu, Z. (2008): Forensic Science International stature and gender estimation using foot measurement. J. For. Sci.; 181: 541-545. 


\section{الملخص العربيى}

\section{دراسة انثرويومترية على القدم والصورة الرقمية لها لتعيين طول القامة على عينة من المصريين

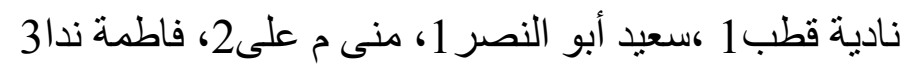

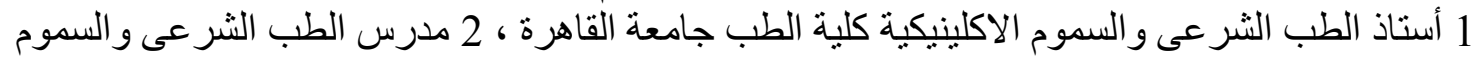

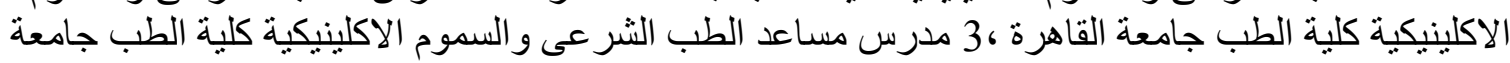
القاهرة

يعتبر تقدير طول القامة فى الجثث الممزقة من الأمور الصعبة خاصة بعد الكو ارث ، و لهذا تم استحداث

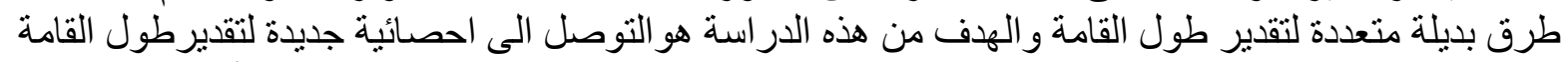

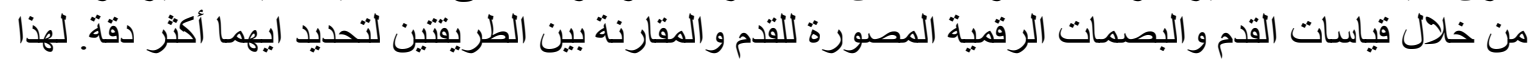

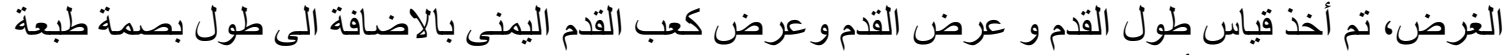

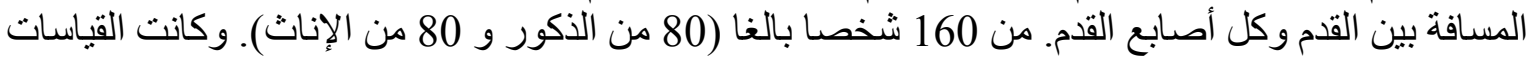

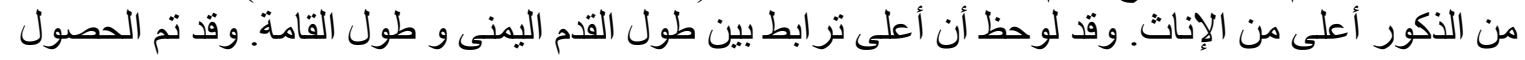

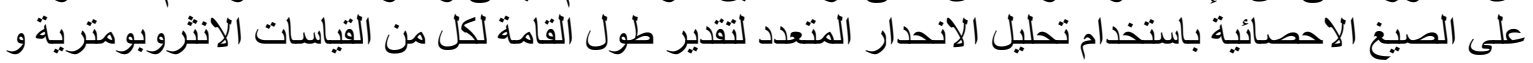

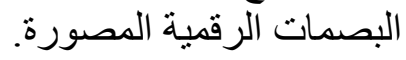

